\title{
Analisis Power Budget pada Jaringan Komunikasi Jarak Jauh Menggunakan SMF 28
}

\author{
Sri Danaryani ${ }^{1 *}$ \\ * Teknik Elektro, Politeknik Negeri Jakarta \\ sdanaryani@gmail.com ${ }^{1}$
}

Article Info
Article history:
Received : 8 November 2018
Revised : 27 November 2018
Accepted : 18 Desember 2018

Keyword:

Bandwidth,

EDFA,

OSNR,

SMF28,

Solution wave.

\begin{abstract}
The fourth generation of optical fibers is wavelength division multiplexing (DWDM), where several wavelengths propagate in a single optical fiber. This technique strongly supports broadband communication that is currently being developed. An optical amplifier (EDFA) is required for transmitted information to be received at the appropriate distance limits. The problem, where EDFA should be located and how to overcome the chromatic dispersion of signals occurs, especially on remote communications using SMF 28. The power budget analysis starts from the calculation of the distance between the amplifier and the strengthening of EDFA using the solution wave equation, where the large dispersion of chromatic fiber and the desired range becomes the determinant of the optical amplifier. Case study for $200 \mathrm{~km}$ of communication distance need three amplifiers with a space of about $80 \mathrm{~km}$. When a $1 \mathrm{GHz}$ bandwidth is converted to 10 $\mathrm{GHz}$, OSNR on each amplifier will decrease by $10 \mathrm{~dB}$
\end{abstract}

Copyright (C) 2018 Journal of Applied Informatics and Computing. All rights reserved.

\section{Pendahuluan}

Tujuan utama dari setiap sistem komunikasi adalah untuk meningkatkan jarak transmisi dan kecepatan (kecepatan data). Seperti sistem komunikasi yang lainnya, sistem komunikasi optik menurut Kaur \& Sarangal juga menghadapi masalah seperti dispersi, atenuasi, kerugian dan efek non linier, yang menurunkan kinerjanya. [1] Efek dari atenuasi akan menurunkan daya sinyal dan efek dispersi mendistorsi bentuk pulsa gelombang cahaya yang merambatkan didalam serat.

Pengaruh jarak komunikasi yang berkaitan dengan redaman dan dispersi merupakan batasan dalam perencanan, sehingga dibutuhkan penguat optikal yang mendukung teknologi multiplexing. Kakalia dan Singh menjelskan bahwa penguat optikal EDFA mempunyai penguatan yang terbaik pada panjang gelombang $1550 \mathrm{~nm}$. EDFA dapat digunakan untuk komunikasi jarak jauh [2]. DWDM menurut Kaur dan Sarangal merupakan teknik untuk meningkatkan kapasitas dan memenuhi kebutuhan bandwidth [1]. EDFA dan DWDM merupakan perkembangan fiber optik generasi ke empat. Untuk komunikasi jarak jauh dengan beberapa panjang gelombang perlu memadukan, Kurkani dan Liu menjelaskan DWDM dan EDFA dimana dibutuhkan lebih dari satu penguat EDFA [3]. Penggunaan penguat amplifier gain (EDFA) pada simulasi perhitungan optical power link budget pada saluran serat optik, dapat memperkuat parameter daya output dan meminimalisir rugi-rugi sehingga sistem jaringan komunikasi serat optik tersebut dapat layak digunakan [4]

Performansi dari sistem dibatasi oleh adanya pelebaran sinyal yang dikirim per satuan panjang dari fiber yang disebut sebagai dispersi kromatis. Makin besar panjang fiber yang digunakan membuat dispersinya makin besar juga. Besar maksimum dipersi kromatis dibatasi pada saat pabrikasi fiber optik agar sinyal yang diterima tidak mengalami cacat gelombang. Untuk memperkecil efek disperse digunakan perangkat mengkompensasi dispersi Dispersion Compensation fiber (DCF) yang diletakan pada span antar amplifier pada jaringan fiber optik single mode. Dengan adanya pengkompensasi disperse menghasilkan disperse kromatis menjadi berkurang [2].

Peletakan DCF pada jaringan fiber optik ada tiga macam. Pertama, diletakan sebelum penguat (pre-DCF). Kedua, diletakan sesudah penguat (post DCF). Ketiga, diletakan sebelum dan sesudah penguat (simetris DCF). Sabina dan Kaur melakukan simulasi untuk jarak komunikasi maksimum $278 \mathrm{~km}$ yang dibagi dalam dua link, dimana 
setiap link menggunakan $116 \mathrm{~km}$ kabel fiber optik SMF28 dan $23 \mathrm{~km}$ menggunakan DCF. Dari hasil simulasi, ditemukan bahwa sistem post DCF dan simetris-DCF bekerja lebih baik daripada sistem pre DCF [5].

Perbandingan signal terhadap noise optik (optical signalto-noise ratio OSNR) dan serat optik nonlinier merupakan faktor penting dalam mengevaluasi kinerja sistem komunikasi serat optik berkecepatan tinggi. [6]. Jarak span EDFA serta OSNR dapat dihitung untuk jarak transmisi yang ditetapkan dan menggunakan SMF multi panjang gelombang [7]

Bila DCF diganti dengan Dispersion Compensasion Unit DCU, permasalahannya adalah jarak span EDFA dan peletakan EDFA dengan DCU seperti apa yang membuat penguatan dapat maksimal dan efektif untuk jarak $200 \mathrm{Km}$, dan apa pengaruhnya span tersebut terhadap OSNR. Tujuan dari penelitian adalah mengetahui pengaruh jarak span EDFA, peletakan EDFA dan DCU, serta ONSR untuk jarak $200 \mathrm{~km}$

\section{METODA PENELITIAN}

Penelitian ini merupakan studi literature dengan perencanaan menggunakan data awal dari perangkat yang umumnya digunakan pada system komunikasi fiber optik. Blok diagram dari perencanaan system dapat dilihat pada gambar 1. Banyak data yang dibutuhkan, misalkan jarak jangkau yang akan direncanakan, jenis fiber optik yang akan digunakan, lebar pulsa yang akan dikirim dan besar disperse maksimum yang boleh terjadi. Disperse menjadi masalah utama, bila dalam system tidak memperhitungkan kemungkinan dispersi dan tidak butuh penguatan, maka perencaan dapat langsung menghitung link budget.

Dengan memperhitungkan disperse maka dianggap system tidak linier lagi. Untuk menghitung link budget, terlebih dahulu harus mempertimbangkan disperse dan teknik kompensasi. Jarak jangkau yang jauh juga harus mempertimbangkan penguatan dan letak penguatan sepanjang jalur, apakah sebelum pengkompensasai satau sesudah pengkomensasi dispesi. Karenanya penyelesaian dengan model tidak linier, atau dengan solition system. Setelah memperhitungkan pengkompensasi dan penguat, selanjutnya dapat dihitung link budget system dan OSNR.

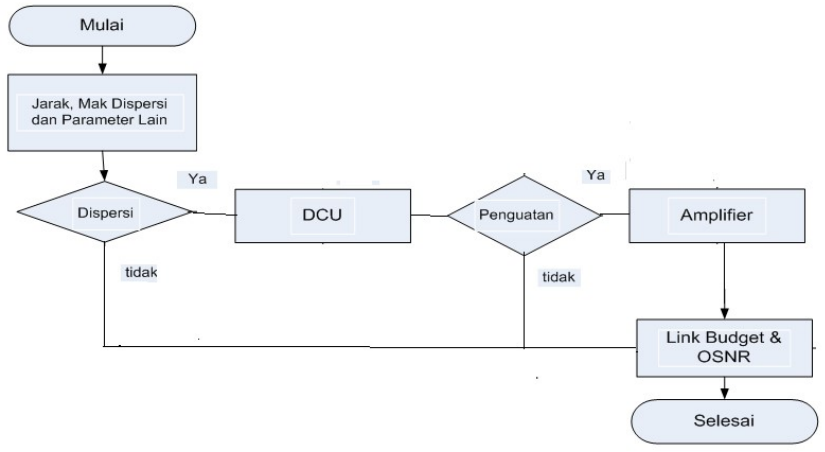

Gambar 1. Blok diagram perencanaan system SKSO
Secara system, perencanaan jaringan optik dengan panjang $200 \mathrm{~km}$ digambarkan seperti pada gambar 2 . Dimana jumlah penguat yang akan digunakan dirancang berdasarkan spesifikasi awal yang dibutuhkan dari system dan batasan yng diinginkan. Dalam gambar 2 penguat semua berada sepanjang jaringan (in line amplifier) dengan jenis yang digunakan EDFA.

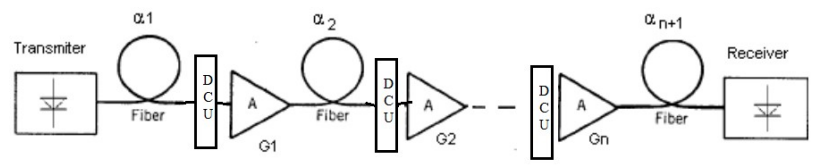

Gambar 2. Blok diagram jaringan SKSO

Jenis kabel otik yang akan digunakan untuk mengetahui parameter redaman dan karakteristik dispersi, besar trafik yang dibawa, pelebaran pulsa yang diperkirakan, sensitivitas penerima untuk BER tertentu. Disisi pengirim perlu dipertimbangkan daya transmit yang sesuai dengan perangkat transmitter dalam hal ini dipilih Dioda Laser yang mempunyai lebar pulsa sangat kecil. Jenis penguat, range daya input penguat dan persyaratan jarak spasi antar amplifer. Batasan dalam rancangan dengan menimbang toleransi dispersi, pinalti dispersi, sensitivitas penerima dan OSNR toleransi. Contoh Spesifikasi perangkat dengan merujuk pada data pabrik, EDFA buatan MRV tipe M316EA dan EM316EDFA, dengan gain sebesar $20 \mathrm{~dB}$. Input LASER $10 \mathrm{dBm}$ dengan tipe QLM3S860SPEC buatan Lasertron.

\section{HASIL PENELITIAN}

Solition asal kata dari solitary wave ditemukan oleh scientis Skotlandia, yang menggambarkan kondisi sistem transmisi non linier yang menjadi batasan dalam perencanaan berkaitan dengan sifat fisika dari perangkat. Dalam rancangan dipilih rancangan mendekati kondisi non linier karena adanya pelebaran sinyal atau disperse. Pelebaran pulsa harus diperhitugkan dan dikompensasi dengan peralatan kompensasi agar sinyal yang diterima tetap dalam kondisi tidak cacat gelombang. Pengkompensasi lebar pulsa disebut sebagai upaya menormalisasi lebar pulsa. Menurut Max Ming, solition wave adalah metode penyelesaian system non linier dengan menormalisasi lebar pulsa To dalam ordo detik [8].

Rancangan atau perencanaan spasi dari spasi EDFA dilakukan untuk transmisi solition jaringan fiber yang panjangnya $200 \mathrm{~km}$ menggunakan kabel SMF 28 dengan besar trafik yang dibawa OC 48 pada $\mathrm{To}=100$ psec. Parameter disain SMF 28 dengan redaman $0,25 \mathrm{~dB} / \mathrm{km}$ dan karakteristik dispersi $18 \mathrm{ps} / \mathrm{nm} . \mathrm{km}$. Sensitivitas penerima $18 \mathrm{dBm}$ untuk BER $10^{-12}$. Receiver overload $-10 \mathrm{dBm}$ untuk BER $10^{-12}$. Daya transmit +7 sampai dengan $+9 \mathrm{dBm}$, toleransi dispersi $1500 \mathrm{ps} / \mathrm{nm}$. Pinalti dispersi $1.5 \mathrm{~dB}$ pada $1500 \mathrm{ps} / \mathrm{nm}$. OSNR toleransi $20 \mathrm{~dB}$ dengan resolusi bandwidth $0.1 \mathrm{~nm}$. EDFA dengan range daya input +3 sampai dengan $-25 \mathrm{dBm}$, gain $20 \sim 14 \mathrm{~dB}$ dan spasi 
amplifier $<\mathrm{Z}_{0} / 7$. Maksimum daya keluaran $+17 \mathrm{dBm}$; Noise Figure $5 \mathrm{~dB}$. DCU mempunyai loss $6 \mathrm{~dB}$ dengan kompensasi dispersi -1100 ps.

Untuk membangun jaringan yang dimaksud, maka akan diperhitungkan attenuasi, dispersi dan dispersi setelah adanya DCU. Dengan jarak 200km, attenuasi kabel sebesar $50 \mathrm{~dB}$. Dispersi kabel $18 \mathrm{ps} / \mathrm{nm} . \mathrm{km}$ dan dispersi toleransi $1500 \mathrm{ps} / \mathrm{nm}$, maka jarak maksimum tanpa DCU sebesar $=$ $(1500 / 18)=83.3 \mathrm{~km}$. Untuk mencapai jarak $200 \mathrm{~km}$ perlu dipasang DCU, dimana jumlah DCU yang akan digunakan sebanyak $(200 / 83.3)=3$. Dengan jarak $200 \mathrm{~km}$ maka dispersi total sebelum dipasang DCU menjadi 3600ps $/ \mathrm{nm}$. Setelah dipasang tiga DCU dimana setiap dDCU mampu mengkompensasi dispersi sebesar $1100 \mathrm{ps} / \mathrm{nm}$, maka dispersi sinyal menjadi $=(3600-3 \times 1100)=300 \mathrm{ps} / \mathrm{nm}$. Nilai ini masih dibawah pinalti sebesar $1500 \mathrm{ps} / \mathrm{nm}$.

Untuk mengkompensasi loss pada serat digunakan penguat optikal untuk menjaga level daya. Hal ini disebabkan efek non linier menjadi sangat kuat dan kemungkinan akan terjadi dispersi, sehingga perlu menggunakan amplifier EDFA.

Letak penguat karena efek non linier perlu ditentukan dengan perhitungan menggunakan Solition [8]. Perhitungan pertama adalah besar koefisien dispersi $\beta_{2}$ dengan mempertimbangkan dispersi kromatis $D_{\text {intra }}$ dari kabel, menggunakan persamaan $\beta_{2}=-\left((\boldsymbol{\lambda} / \boldsymbol{\omega})\right.$. $\left.D_{\text {intra }}\right)$, didapat $\quad \beta_{2}$ $=-23 \mathrm{psec}^{2} / \mathrm{km}$.

Untuk menentukan jarak spasi EDFA, perlu direncanakan terlebih dahulu daya yang akan diluncurkan ke dalam serat optik. Daya yang akan diluncurkan kedalam serat optik diperhitungkan dengan adanya konstanta normalisasi lebar pulsa To. Besar To diambil pada rancangan umumnya untuk bandwidth $10 \mathrm{Ghz}$ atau To menjadi 100 psec. Daya minimum yang diluncurkan kedalam fiber menggunakan persamaan $\mathrm{P}=\left[\beta_{2}\right] /\left(\gamma \mathrm{To}^{2}\right)$, didapat $\mathrm{P}$ sebesar $1.15 \mathrm{~mW}$.

Jarak antar (spasi) EDFA mempunyai syarat $\mathrm{La}<<\mathrm{Z} 0$, dimana panjang lintasan $Z$ o dengan $\beta_{2}$ dan $T_{0}$ yang ada, didapat $Z 0=\pi / 2 \cdot T_{0}^{2} /\left[\beta_{2}\right]=682.6 \mathrm{~km}$. Syarat spasi yang telah ditentukan $Z_{\mathrm{o}} / 7$, maka jarak spasi menjadi $97.5 \mathrm{~km}$. Karena $L_{a}<<Z_{0}$, panjang fiber untuk sampai ke penguat EDFA atau spasi antar EDFA dan dengan mempertimbangkan jarak DCU, maka dipilih $\mathrm{L}_{\mathrm{a}}=80 \mathrm{~km}$.

Setelah ditetapkan spasi jarak EDFA $80 \mathrm{~km}$, maka untuk jarak 200km dibutuhkan $(200 / 80)=3$ EDFA. Jumlah EDFA sama dengan jumlah DCU, dimana peletakannya tergantung pada kuat sinyal yang diterima. Dengan adanya 3 EDFA dan 3 DCU, maka jarak $200 \mathrm{~km}$ dibagi dalam tiga stage. Jarak antar stage dirancang berdasarkan $\mathrm{L}_{\mathrm{a}}<<\mathrm{Z}_{0}$, yaitu $80 \mathrm{~km}, 80$ $\mathrm{km}$ dan $40 \mathrm{~km}$.

Stage 1, attenuasi yang dihasilkan $0.25 \mathrm{~dB} / \mathrm{kmx} 80 \mathrm{~km}=$ $20 \mathrm{~dB}$, untuk itu dipilih gain $\mathrm{G}=20 \mathrm{~dB}$ atau terjadi penguatan 100 , maka $\alpha_{\mathrm{f}} \mathrm{L}_{\mathrm{a}}=\ln 100=4$.6. Faktor atenuasi rata-rata dari fiber dihitung menggunakan persamaan 1 .

$$
\rho=\left(1-e^{-\alpha_{f} L_{a}}\right) /\left(\alpha_{f} L_{a}\right)
$$

Dengan adanya faktor attenuasi, maka daya yang akan ditrasmisikan menjadi $\mathrm{Ptx}=1 / \boldsymbol{\rho}$, yaitu $7.38 \mathrm{mWatt}$ atau $8.68 \mathrm{dBm}$. Nilai $8.68 \mathrm{dBm}$ masuk dalam kisaran daya pancar transmiter antara $7-9 \mathrm{dBm}$.

Dengan besar dispersi kromatis 18 ps/nm.km maka jarak penguat EDFA $80 \mathrm{~km}$, tetapi karena jalur lintasan hanya 200 $\mathrm{km}$, maka 3 stage dengan jarak stage penguat 1 sejauh 40 $\mathrm{km}$, stage 2 sejauh $80 \mathrm{~km}$ dan stage 3 sama dengan stage 2 . Losses per stage adalah attenuasi kabel, loss dari DCU $6 \mathrm{~dB}$ dan loss tambahan yang diperhitungkan andai terjadi kerusakan pada kabel yang disebut sebagai Margin yangbesarnya $1.5 \mathrm{~dB}$. Stage 1 dengan jarak $40 \mathrm{~km}$, losses yang dihasilkan $=(40 \mathrm{kmx} 0.25 \mathrm{~dB} / \mathrm{km})+1.5 \mathrm{~dB}+6 \mathrm{~dB}=$ $17.5 \mathrm{~dB}$.

Dengan daya transmit $7.5 \mathrm{dBm}$, maka daya keluaran di ujung stage 1 sebesar $(7-17.5)=-10.5 \mathrm{dBm}$. Sinyal ini diperkuat menggunakan EDFA dengan besar penguatan 20 $\mathrm{dB}$, sehingga keluaran EDFA menjadi $9.5 \mathrm{dBm}$. Keluaran ini akan menjadi input untuk stage 2. Dengan cara perhitungan yang sama, keluaran dari amplifier stage 2 dan satge 3 untuk jarak $80 \mathrm{~km}$ berturut-turut adalah $2 \mathrm{dBm}$ dan -5.5 $\mathrm{dBm}$. Input penguat EDFA pada setiap stage yaitu $-10,5$ $\mathrm{dBm} ;-18 \mathrm{dBm}$ dan $-25.5 \mathrm{dBm}$. Stage satu dan dua memenuhi kriteria EDFA yang kisaran input dari +3 sampai dengan -25 $\mathrm{dBm}$, karenanya EDFA dapat diletakan sebelum DCU. Stage ketiga dengan input EDFA $-25.5 \mathrm{dBm}$ dibawah range EDFA, untuk mengatasinya maka amplifier EDFA diletakan setelah DCU. Untuk mempermudah rancangan, semua stage diberlakukan sama, yaitu dipasang terlebih dahulu DCU dilanjut dengan EDFA. Keluaran dari EDFA stage ketiga adalah $-11.5 \mathrm{dBm}$,

Perancangan dilanjutkan dengan menghitung OSNR pada setiap stage menggunakan persamaan 2, [9].

$$
\text { OSNR }=P_{\text {in }} /\left(N F_{\text {stage }} h f \Delta f\right)
$$

dimana NFstage : noise figure dari stage ; $\mathrm{h}$ : konstanta Plank $6.6260 \times 10^{-34} \mathrm{~J}-\mathrm{s} ; \quad \mathrm{f}$ : frekuensi optikal $\mathrm{THz}$; $\Delta f$ : bandwidth pada saat mengukur NF, besarnya mayoritas $0,1 \mathrm{~nm}$ atau $10 \mathrm{GHz}$.

Hasil perhitungan OSNR stage 1 dengan NF $5 \mathrm{~dB}$, Bandwidth $1 \mathrm{GHz}$ dan daya sebelum masuk ke dalam EDFA $-10 \mathrm{dBm}$, maka OSNR sebesar $43.9 \mathrm{~dB}$. OSNR Stage 2 dan 3 berturut-turut $36.4 \mathrm{~dB}$ dan $27.58 \mathrm{~dB}$. Dari hasil yang didapat OSNR final pada stage 1 sebesar $43.41 \mathrm{~dB}$, stage 2 sebesar $35 \mathrm{~dB}$ dan stage 3 sebesar $28.9 \mathrm{~dB}$. 


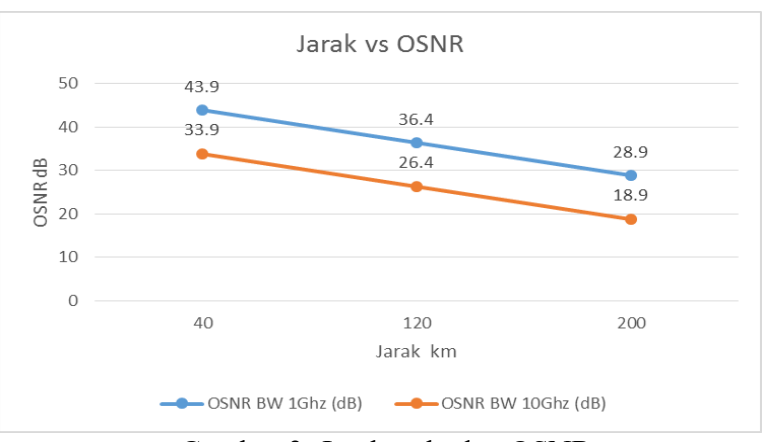

Gambar 3. Jarak terhadap OSNR

Bila bandwidth akan dikembangkan dari $1 \mathrm{GHz}$ menjadi $10 \mathrm{GHz}$. Hasilnya yang didapat OSNR system keseluruhan akan turun menjadi $33.9 \mathrm{~dB}$ pada stage 1, 26.4 $\mathrm{dB}$ pada stage 2 dan $18.9 \mathrm{~dB}$ pada stage 3 . Bila dibandingkan dengan OSNR pada $1 \mathrm{GHz}$ terjadi penurunan sebesar $10 \mathrm{~dB}$. Hal ini dikarenakan bandwidth dinaikan $10 \mathrm{x}$ dari bandwidth awal maka penurunan OSNR juga turun sebesar $10 \mathrm{~dB}$ ( $10 \log 10)$ dari kondisi sebelumnya. Kecenderungan penurunan OSNR pada setiap dapat dilihat pada gambar 3 .

Sinyal dapat diterima pada perangkat penerima bila level sinyal yang masuk lebih besar dari pada sensitivitas penerima, atau dengan kata lain margin positip. Perhitungan ini merupakan perhitungan yang biasa digunakn pada sistem telekomunikasi untuk memastikan bahwa rancangan sudah dapat diaplikasikan bila margin positip. Dari hasil hitungan didapat level sinyal keluaran EDFA stage ketiga sebesar -5 $\mathrm{dBm}$, dibandingkan dengan sensitivitas penerima sebesar $18 \mathrm{dBm}$, maka margin dari dua sinyal tersebut menjadi $(-5-$ $(-18))=13 \mathrm{~dB}$. Nilai ini positip, sehingga rancangan ini dapat direalisasikan.

Hasil akhir dari rancangan yang memuat nilai OSNR, attenuasi dan keluaran EDFA secara diagram seperti gambar 4. Pada gambar terlihat span ke 1, ke 2 dan ke 3, yaitu dengan jarak $40 \mathrm{Km}, 80 \mathrm{Km}$ dan $80 \mathrm{Km}$, pada bagan input penguat EDFA diperlihatkan sinyal sebelum dikuatkan dan dibagian keluaran merupakan sinyal yang telah dikuatkan.

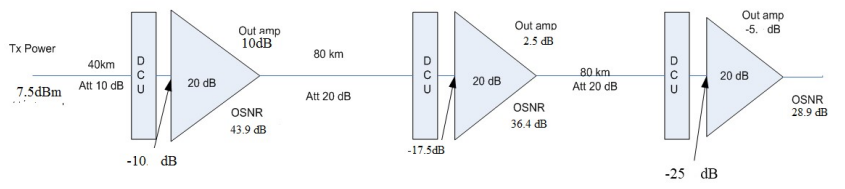

Gambar 4. Diagram OSNR dan Gain dari hasil perhitungan

Selain OSNR pada setiap stage, dapat juga dihitung Total OSNR dari $\mathrm{N}$ stage menggunakan persamaan 3.

$\frac{1}{O S N R_{\text {final }}}=\frac{1}{O S N R_{1}}+\frac{1}{O S N R_{2}}+\ldots . .+\frac{1}{O S N R_{N}}=\sum_{i} \frac{1}{O S N R_{i}}$

Pada stage 1 yang dihitung hanya pengaruh dari stage 1 . Pada stage 2, perhitungan OSNR total dengan menggabungkan OSNR 1 dan 2, yang sudah didapat dari perhitungan sebelumnya. Hasilnya dapat dilihat pada tabel 1, dan grafik yang dihasilkan dapat dilihat pada gambar 5 .

TABEL 1

OSNR TOTAL DARI SETIAP STAGE

\begin{tabular}{|c|c|c|c|}
\hline \multirow{2}{*}{ OSNR dB } & \multicolumn{3}{|c|}{ Jarak (km) } \\
\cline { 2 - 4 } & 40 & 120 & 200 \\
\hline OSNR Total1 GHz & 43.9 & 13 & 10.7 \\
\hline OSNR Total10 GHz & 33.9 & 11.7 & 9.2 \\
\hline
\end{tabular}

Dengan data pada tabel 1, dapat dilihat kecenderungan OSNR total dimulai dari jarak $40 \mathrm{~km}$ hingga $200 \mathrm{~km}$, dimana OSNR total akan makin mengecil dengan jarak makin jauh. Kecenderungan dapat dilihat pada gambar Hal ini sejalan dengan makin jauh jarak, redaman makin besar, sehingga daya yang diterima pada DCU dan Amplifier juga makin kecil. Untuk itu perlu dibatasi jarak jangkau agat tetap mendapatkan keluaran yang sesuai OSNR yang dibutuhkan.

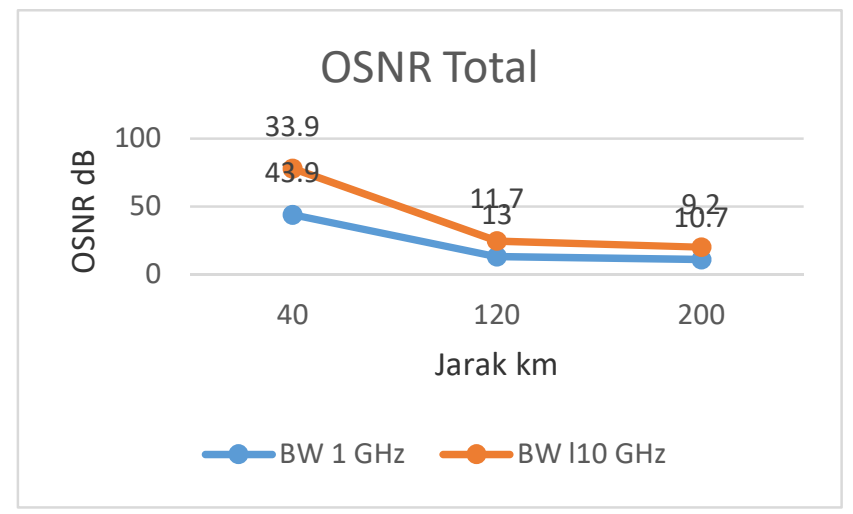

Gambar 5. OSNR Total

\section{KESIMPULAN}

Dari hasil pembahasan perancangan dan perhitungan yang telah dilakukan, simpulannya bahwa

1. Peletakan amplifier dalam jaringan fiber optik, yang dalam contoh sejauh $200 \mathrm{~km}$, sangat dipengaruhi keluaran dari EDFA. Dengan menggunakan kabel SMF 28 dengan redaman kabel $0.25 \mathrm{~dB} / \mathrm{km}$, keluaran stage ketiga dari EDFA adalah $-5 \mathrm{dBm}$ dan sensitivitas $18 \mathrm{dBm}$, sinyal ini kemudian masuk ke penerima dan menghasilkan margin posittip sebesar $13 \mathrm{~dB}$.

2. OSNR total pada stage ketiga sebesar $10.7 \mathrm{dBdB}$ dengan bandwidth yang digunakan $1 \mathrm{GHz}$. Bandwidth ditingkatkan menjadi $10 \mathrm{Ghz}$ membuat OSNR total pada stage ketiga menjadi $9.2 \mathrm{~dB}$. OSNR yang rendah menandakan perbedaan level sinyal dengan level noise yang dihasilkan juga makin kecil.

3. Secara keseluruhan rancangan ini dapat diteruskan karena nilai margin daya masih postif. 


\section{DAFTAR PUSTAKA}

[1]. Manpreet Kaur, Himali Sarangal, Simulative Investigation of $32 \times 10,32 \times 20$ and $32 \times 40 \mathrm{~Gb} / \mathrm{s}$ DWDM Systems with Dispersion Compensating Fibers; International Journal of Signal Processing, Image Processing and Pattern Recognition, Vol.8, pp.127-134, 2015

[2]. Sahil Kakalia, Munish Singh, "Performance Analysis of DWDM System Having 0.8- Tbps Date Rate with 80 Channels," Indian Journal of Science and Technology, vol 9, December, 2016.

[3]. Alpina Kulkarni, Paolo Liu, (2015) Fiber Systems Dense Wavelength Division Multiplexing (DWDM). [Online]. Tersedia https://slideplayer.com/slide/4178696/.

[4]. Lucia Jambola, "Simulasi Anggaran Daya Sistem Komunikasi Serat Optik Berbasis MATLAB 7.5," JETT Jurnal Elektro Telekomunikasi Terapan, Juli, 2016,

[5]. Sabina, Manpreet Kaur, "Performance Comparison of Pre-, Post-, and Symmetrical Dispersion Compensation using DCF for 64 x $40 \mathrm{~Gb} / \mathrm{s}$ DWDM System, " SSRG International Journal of Electronics and Communication Engineering (SSRG-IJECE), vol 4, pp 236-244, Juli, 2017.

[6]. Ziyi Wang, Aiying Yang, "OSNR and nonlinear noise power estimation for optical fiber communication systems using LSTM based deep learning technique ", Optics Express, vol. 26, pp. 21346-21357, 2018.

[7]. Jian Zhao, Inwoong Kim. "Minimizing the Number of Spans for Terrestrial Fiber-Optic Systems Using QuasiSingle-Mode Transmission," IEEE Photonics Journal, vol 10, Feb, 2018.

[8]. Max Ming, Kang Liu, Priciples and Application of Optical Communication, McGraw Hill, USA, 1996.

[9]. Gumataste Aashwin, Antony Tony, DWDM Network Designs and Engineering Solutions, Ciscopress.com, 2002. 